\title{
Prediction of Joint Shear Strength of RC Beam-Column Joint Subjected to Seismic loading using Artificial Neural Network.
}

\section{Predicción de la resistencia al corte de la articulación de la articulación viga-columna RC sometida a carga sísmica utilizando una red neuronal artificial}

\author{
Shreyas Alagundi ${ }^{1}$, Palanisamy. $T^{2}$ \\ ${ }^{1}$ Department of Civil Engineering, National Institute of Technology Karnataka \\ Surathkal, India
}

Corresponding author mail id: shreyas.193st003@nitk.edu.in

\section{ABSTRACT}

BC (Beam-column) joints are critical locations in RC frames subjected to severe earthquake attack. Failure of Joint which is of shear type is not an appreciable structural behaviour. Present study proposes an artificial neural network model for joint shear strength of reinforced exterior BC connections. ANN is a component of artificial intelligence which mimics the human brain characteristics and learns from previous experiences and has recently gained popularity in the area of civil engineering. A dataset of specimen dimensions, material properties, Area of Reinforcement used in Beam and column and failure mode are established from past experimental investigations on BC joints subjected to seismic type loading and are used for ANN modelling. ANN model is developed with eleven input parameters to predict the Joint shear strength of Exterior BC Joints. The Proposed model is compared with the equation given in design codes and empirical formula. Proposed ANN model has predicted the shear strength more accurately. Thus the proposed ANN model can be used for Prediction of Joint shear strength of Reinforced concrete exterior BC joints subjected to seismic loading.

Keywords- Joint Shear strength, Beam-Column Joint, Artificial neural network

\section{RESUMEN}

Las juntas BC (viga-columna) son ubicaciones críticas en los marcos RC sometidos a un severo ataque sísmico. La falla de la junta que es de tipo cortante no es un comportamiento estructural apreciable. El presente estudio propone un modelo de red neuronal artificial para la resistencia al corte de las conexiones exteriores reforzadas de BC. ANN es un componente de inteligencia artificial que imita las características del cerebro 
Sustainability, Agri, Food and Environmental Research, (ISSN: 0719-3726), 10(X), 2022: http://dx.doi.org/

humano y aprende de experiencias previas y recientemente ha ganado popularidad en el área de la ingeniería civil. Se establece un conjunto de datos de las dimensiones de la muestra, las propiedades del material, el área de refuerzo utilizada en el modo de viga y columna y de falla a partir de investigaciones experimentales pasadas en juntas BC sujetas a cargas de tipo sísmico y se utilizan para el modelado ANN. El modelo ANN se desarrolla con once parámetros de entrada para predecir la resistencia al corte de las juntas exteriores BC. El modelo propuesto se compara con la ecuación dada en los códigos de diseño y la fórmula empírica. El modelo ANN propuesto ha predicho la resistencia al corte con mayor precisión. Por lo tanto, el modelo ANN propuesto se puede utilizar para la predicción de la resistencia al corte de la junta de juntas BC exteriores de hormigón armado sometidas a carga sísmica.

Palabras clave: resistencia al corte de la articulación, articulación viga-columna, red neuronal artificial

\section{INTRODUCTION}

Beam-column joints are the lateral and vertical load resisting members in RC frame structures; however, their behaviour differs when subjected to gravitational and seismic loading. BC joints are treated as crucial locations of failure as it frequently prompts fractional or absolute breakdown of the entire structure. Designers need to painstakingly think about joint shear strength and the ductility performance of $\mathrm{BC}$ joints to ensure that the brittle shear failure at the joint region should not happen. Inconsistencies in existing design standards for predicting the Joint shear strength of RC beam-column connections (IS-13920 : 2016, ACI-352 : 2002 and AIJ : 1999) draws attention in this regard. Many researchers have worked on experimental and analytical investigations on Joint shear strength of BC joint. Predicting the Joint shear capacity is complicated due to the involvement of various parameters attributing to it. Many experiments have been done to investigate the parameters which influence the Joint Shear capacity and to improve it. An Experimental study conducted by Alva et al. (2007) showed that shear capacity is affected more by concrete compression strength than by the number of stirrups, considering the same dimensions for both beams and columns. It is also found that the stirrups did influence the behaviour of the connections by defining their displacements when connection capacity is reached (Alva et al. 2007). H.F Wong et al. (2008) conducted an experimental study and concluded that the joint shear strength decreases significantly as the beamcolumn depth ratio increases. It is found that the joint shear strength is reduced by about $50 \%$ when the beam-column depth ratio increases from 1.0 to 2.0 and when it is over 2.0 , no further obvious decrease in the shear strength of joints can be observed (Wang and Kuang, 2008). Effect and influence of various parameters like Joint shear reinforcement, 
Sustainability, Agri, Food and Environmental Research, (ISSN: 0719-3726), 10(X), 2022: http://dx.doi.org/

Column axial load, and Anchorage of Beam bars anchoring into the joint are still not clear, and in this point of view, research needs to be progressed.

\section{MATERIALS AND METHODS}

Artificial Neural Network (ANN)

ANN is a specialist framework supplementing the representation of human neurological framework utilized for tackling complex issues. The present study focuses on ANN modelling, which consists of three layers (Input layer, Hidden layer and Output layer). Schematic diagram of an artificial neuron is shown in Fig. 1 . Once the network is trained over a number of iterations, then the trained network can be used over a new set of inputs. Eq. (1) describes the mode of operation of a network. Where $i_{x}$, scaled input value transmitted from the $x^{\text {th }}$ input neuron; $\mathrm{H}_{\mathrm{n}}$, activity level generated at the nth hidden neuron; $\mathrm{O}_{\mathrm{y}}$, activity level generated at the $y^{\text {th }}$ output neuron; $w_{x, n}$ and $v_{n, y}$ weights on the connections to the hidden and output layers of neurons respectively. $b_{n}$ and $b_{y}$ are weighted biases and $f[]$ is the activation function.

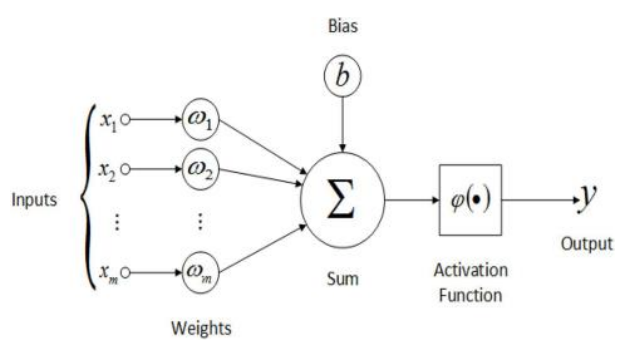

Fig. 1 Artificial Neuron

$$
H_{n}=f\left(w_{x, n} * i_{x}\right)+b_{n} ; O_{y}=f\left(v_{n, y} * H_{n}\right)+b y
$$

\section{Experimental Database}

An experimental database comprising experimental RC beam-column joints have been collected from the published literature. The dataset contain 74 specimens of exterior BC joints (Kuang and Wong, 2006; Tsonos, 2005; Chalioris et al. 2008; Karayannis and Sirkelis, 2008; Wong and Kuang, 2008; Cong, 2006; Vatani-Oskouei, 2010; Hwang et al. 2005; Antonopoulos and Triantafillou, 2003; Parker et al. 1997; Ehsani and Alameddine, 1991; Hamil and Scott; Alva et al. 2007) "Design A consistent set of criteria is applied for all the collected specimens; (1) only exterior BC joints are chosen. (2) Specimens having out of plane elements such as beams in the transverse direction, slab etc. are avoided. (3) Specimens having eccentricity among column and beam are avoided. (4) The failure modes of specimens are of joint shear failure. 
Sustainability, Agri, Food and Environmental Research, (ISSN: 0719-3726), 10(X), 2022: http://dx.doi.org/

Input Parameters considered for neural network modelling

In the present study, Joint width $\left(b_{j}\right)$, Joint depth $\left(h_{c}\right)$, Compressive strength of concrete $\left(f_{c}\right)$, Beam Reinforcement at Top ( $\left.T_{\text {Ast }}\right)$, Beam Reinforcement at Bottom ( $\left.B_{\text {Ast }}\right)$, Beam length $(L)$, Yield strength of beam bars $\left(f_{y b}\right)$, Joint Shear Reinforcement Index $\left(\varphi_{s}\right)$, Column axial load level $\left(P_{y}\right)$, Beam bar index $\left(x_{b}\right)$, Beam-Column depth ratio $\left(h_{b} / h_{c}\right)$ are considered for Inputs of the neural network.

Effective joint width is calculated based on ACI-352 Recommendations (2002) which is given as the least of Eq. (2). Where, $h_{c}=$ column depth, $b_{c}=$ width of the column normal to the loading direction, $b_{b}=$ beam width, $\mathrm{m}=0.3$, for joints where the eccentricity between the beam centre line and the column centroid exceeds $b_{c} / 8$ and $m=0.5$ for all other cases ( $\mathrm{ACl}$ 352 : 2002). As mentioned by various design codes, Joint depth is the overall depth of the column in the direction of the horizontal shear to be considered.

$$
b_{j}=\frac{b_{b}+b_{c}}{2} ; b_{j}=b_{b}+\sum \frac{m \cdot h_{c}}{2} ; b_{j}=b_{c}
$$

Cube strength is converted into cylindrical strength from the assumption that Cylindrical Compressive strength equals to $80 \%$ of the cube compressive strength. Horizontal Shear reinforcement Index $\left(\varphi_{h}\right)$ and Vertical shear Reinforcement Index $\left(\varphi_{v}\right)$ are considered and Sum of it is represented in Eq. (3) as Joint Shear Reinforcement Index ( $\left.\varphi_{s}\right)$ (Tung et al. 2014). $A_{s h}$ is area of shear reinforcement in the joint and $A_{s v}$ is area of intermediate column reinforcements. $f_{y h}$ and $f_{y v}$ are yield strength of shear and Column intermediate reinforcement. Column load is taken in the form of Column axial load level which is shown by Eq. (4) (Tung et al. 2014).

$$
\begin{gathered}
\left(\varphi_{h}\right)=\frac{A_{s h} f_{y h}}{b_{j} h_{c} f_{c}} \quad ; \quad\left(\varphi_{v}\right)=\frac{A_{s v} f_{y v}}{b_{j} h_{c} f_{c}} ;\left(\varphi_{s}\right)=\varphi h+\varphi_{v} \\
\text { Column axial load level }\left(P_{y}\right)=\frac{N}{b_{j} h_{c} f_{c}}(4)
\end{gathered}
$$

Tung et al. (2014) considered a parameter called Beam bar index ( $\mathrm{x}_{\mathrm{b}}$ ) based on reinforcement-concrete bond condition. As it is mention by Tung et al. (2014), its value should not exceed beyond 0.4. In the present study Beam bar index is used as Input parameter and which is shown by Eq. (5). $\mathrm{n}_{\mathrm{b}}$ is the number of reinforcing bars at top and bottom of the beam, $d_{s b}$ is the diameter of bar. According to strut-and-tie mechanism, the angle of inclination of diagonal strut relies upon the depth of beam and column. The angle of inclination of a diagonal strut is defined in the form of joint aspect ratio, i.e., the ratio of beam depth $\left(h_{b}\right)$ to column depth $\left(h_{c}\right)$ and it is considered as one of the parameters )(Tung et al. 2014).

$$
\text { Beam bar index }=\frac{\mathrm{n}_{\mathrm{b}} \mathrm{d}_{\mathrm{sb}}}{\mathrm{b}_{\mathrm{b}}}\left(\frac{\mathrm{h}_{\mathrm{c}}}{\mathrm{h}_{\mathrm{b}}}\right) \leq 0.4
$$

Joint shear Strength $(T)$ is output for the neural network. The joint shear force, Jtexp are either determined utilizing the greatest applied load measured from the experiment or taken from 
Sustainability, Agri, Food and Environmental Research, (ISSN: 0719-3726), 10(X), 2022:

http://dx.doi.org/

the announced values in the literature. $80 \%$ of the total beam height $h_{b}$ is assumed as the moment arm of the beam section in the calculation. $\mathrm{T}$ is calculated by dividing Joint shear force by Area of joint that is $\left(b_{j} * h_{c}\right)$.

\section{Pre-Processing of data}

The way in which the data is presented greatly influences the performance of neural network. Statistics of the datasets is presented in Table 1. Data are normalized using Eq. (6). $x_{n}$ is the normalized value of the input value $x_{i} . x_{m i n}$ and $x_{\min }$ are the minimum and maximum values of the variable. Further, the data is divided into three sets (training, testing, and validation data). Data considered for training comprise varying values covering most extreme to the least reach. $60 \%$ of the data are taken for training purpose, $20 \%$ of the data are taken for testing purpose, and $20 \%$ of the data are taken for Validation purpose.

$$
x_{n}=\frac{x_{i}-x_{\min }}{x_{\max }-x_{\min }}
$$

Table 1: Statistics of database

\begin{tabular}{|c|c|c|c|c|c|c|c|c|c|c|c|c|}
\hline $\begin{array}{c}\text { Input } \\
\text { parameters }\end{array}$ & $\begin{array}{l}\text { Joint } \\
\text { width } \\
\text { (bj) }\end{array}$ & $\begin{array}{l}\text { Joint } \\
\text { depth } \\
\left(h_{c}\right)\end{array}$ & $\begin{array}{l}\text { Compressive } \\
\text { strength of } \\
\text { concrete }\left(f_{c}\right)\end{array}$ & $\begin{array}{c}\text { Beam } \\
\text { Reinforcement } \\
\text { at Top }\left(T_{\text {Ast }}\right)\end{array}$ & $\begin{array}{c}\text { Beam } \\
\text { Reinforcement } \\
\text { at Bottom } \\
\text { (B } \text { Bst })\end{array}$ & $\begin{array}{c}\text { Beam } \\
\text { length }(L)\end{array}$ & $\begin{array}{c}\text { Yield } \\
\text { strength } \\
\text { of beam } \\
\text { bars } \\
(\text { fyb })\end{array}$ & $\begin{array}{l}\text { Joint Shear } \\
\text { Reinforcement } \\
\text { Index ( } \varphi s \text { ) }\end{array}$ & $\begin{array}{c}\text { Column } \\
\text { axial } \\
\text { load } \\
\text { level } \\
\text { (Py) }\end{array}$ & $\begin{array}{l}\text { Beam } \\
\text { bar } \\
\text { index } \\
(x b)\end{array}$ & $\begin{array}{c}\text { Beam- } \\
\text { Column } \\
\text { depth } \\
\text { ratio } \\
(\mathrm{hb} / \mathrm{hc})\end{array}$ & $\begin{array}{l}\text { Joint } \\
\text { shear } \\
\text { strength } \\
(\mathrm{T})\end{array}$ \\
\hline Unit & $\mathrm{mm}$ & $\mathrm{mm}$ & $\mathrm{MPa}$ & - & - & $\mathrm{mm}$ & $\mathrm{MPa}$ & - & - & - & - & $\mathrm{MPa}$ \\
\hline Min & 100 & 150 & 15 & $0.262 \%$ & $0.262 \%$ & 840 & 300 & 0 & 0 & 0.067 & 1 & 1.8 \\
\hline Mean & 250.03 & 284.14 & 41.66 & $0.99 \%$ & $0.99 \%$ & 1263.6 & 507.78 & 0.52 & 0.08 & 0.19 & 1.42 & 4.8 \\
\hline STD & 76.98 & 69.08 & 19.79 & $0.37 \%$ & $0.37 \%$ & 350.78 & 61.57 & 0.58 & 0.06 & 0.06 & 0.26 & 1.78 \\
\hline
\end{tabular}

\section{ANN Modeling}

The proposed ANN model, which operates in MATLAB, is constructed by MATLAB code. A single ANN architecture is created with the hidden layer neurons fixed by experimentation (trial and error) to accomplish the best performing model. In the present study, the training algorithm of backpropagation type is used in feed-forward with single hidden layer, and gradient descent technique is used to minimize the error. The network is trained utilizing the Levenberg Marquardt algorithm. The activation functions used in the hidden layer and output layers are tansig and purelin respectively.

\section{Performance of Neural network}

The ANN model performance with varying number of hidden neurons, i.e., from 5 neurons to 14 neurons in the hidden layer is evaluated for the network. It is noticed that the ANN model with 12 neurons in the hidden layer had minimal error showing good correlation between 
observed and predicted shear strengths in comparison to other networks. Subsequent to training the network model, weights and biases of the network are fixed (Asteris et al. 2016; Winston and Oreta, 2004; Armaghani et al. 2019; Arafa and Alqedra, 2011) and Structure of the ANN has 11 nodes in Input layer, 12 nodes in hidden layer and one node in output layer and a node for Bias in hidden and output layer as it is shown in Fig. 2a. The Schematic architecture of ANN generated in MATLAB is shown in Fig. $2 b$.
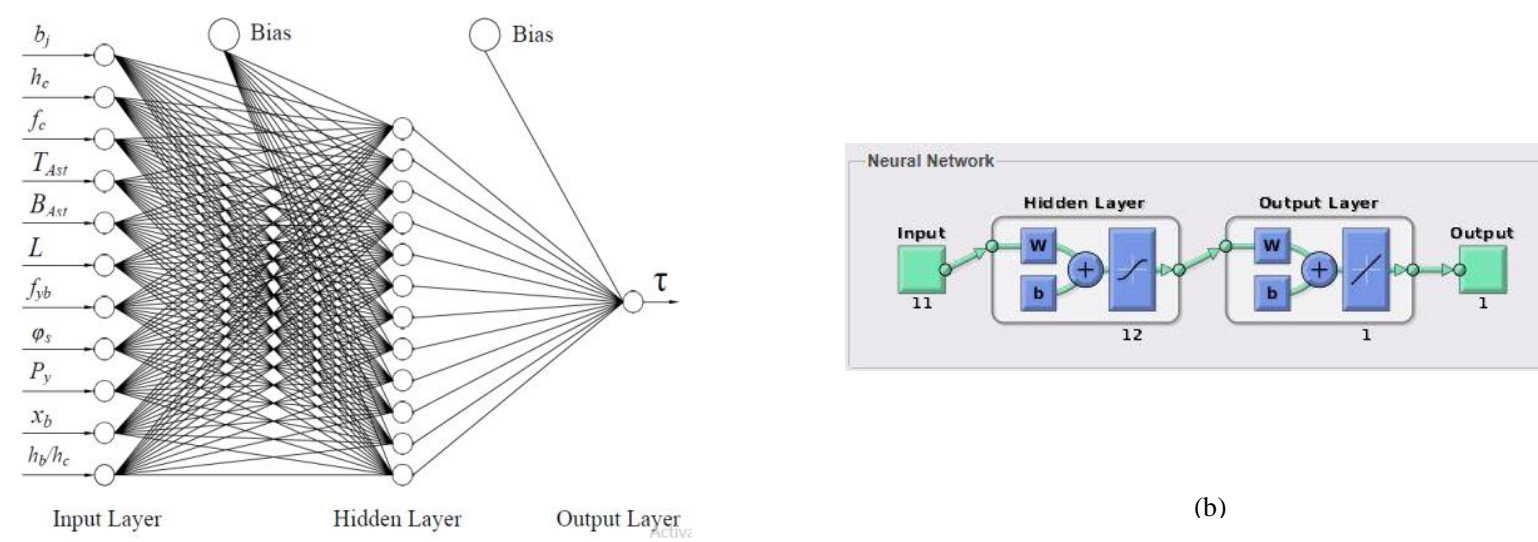

(b)

(a)

Fig. 2 Architecture of ANN

\section{RESULTS AND DISCUSSION}

ANN model performance in this study is expressed in terms of statistical measures. The capability of the approach is checked by correlation coefficient (CC), Root Mean Square Error (RMSE) and Scatter Index (SI), which are defined as shown in Eq. (7) to Eq. (9).

$$
\begin{aligned}
& \mathrm{CC}=\left[\sum_{\mathrm{i}=1}^{\mathrm{n}}\left(\mathrm{O}_{\mathrm{i}}-\overline{\mathrm{O}_{\mathrm{i}}}\right)\left(\mathrm{P}_{\mathrm{i}}-\overline{\mathrm{P}_{\mathrm{i}}}\right)\right] /\left[\sqrt{\sum_{\mathrm{i}=1}^{\mathrm{n}}\left(\mathrm{O}_{\mathrm{i}}-\overline{\mathrm{O}_{\mathrm{i}}}\right)^{2}\left(\mathrm{P}_{\mathrm{i}}-\overline{\mathrm{P}_{\mathrm{i}}}\right)^{2}}\right] \\
& \mathrm{RMSE}=\sqrt{\frac{\sum_{\mathrm{i}=1}^{\mathrm{n}}\left(\mathrm{O}_{\mathrm{i}}-\overline{\mathrm{P}_{\mathrm{i}}}\right)^{2}}{\mathrm{n}}} \mathrm{X} 100 \quad(8) ; \quad \mathrm{SI}=\frac{\text { RMSE }}{\overline{\mathrm{O}_{1}}}
\end{aligned}
$$

Where $\mathrm{O}_{\mathrm{i}}$ and $\mathrm{P}_{\mathrm{i}}$ are the observed and predicted shear strength values respectively. $\overline{\mathrm{O}}_{1}$ and $\overline{\mathrm{P}_{\mathrm{i}}}$ are the average observed and predicted shear strength values respectively. $\mathrm{n}$ is the number of data. The performances of the ANN model in terms of statistical measures are shown in Table 2. Root mean square error and scatter index values show that error in the prediction is very less. Fig. $3 a, 3 b$ and $3 c$ are the $\mathrm{CC}$ plots for training, testing and validation data. CC value for testing, training and validation are $99.1 \%, 97.24 \%$ and $96.93 \%$ respectively show that the proposed model has predicted the Joint shear strength as close to Actual experimental values. Fig. 4a, 4b, 4c are the CC plot for actual values v/s predicted values of full data set, Error histogram and Graph of predicted v/s accurate shear strength values. CC $=98.24 \%$ in Fig. $4 a$ shows that Prediction values have a good correlation with actual value. About $83 \%$ of the predictions of the ANN model lie within the $+/-9 \%$ error (Fig. $4 \mathrm{~b}$ ). Comparison of proposed 
Sustainability, Agri, Food and Environmental Research, (ISSN: 0719-3726), 10(X), 2022:

http://dx.doi.org/

ANN model with ACI, IS, AIJ codes and empirical formula by Tung et al. 2014 is done by plotting the scattered plots in Fig 5. Diagonally arranged less scattered plot indicates the good correlation between the data and hence show the good prediction.

Table 2: Statistical measures

\begin{tabular}{cccc}
\hline Statistical measures & Training & Testing & Validation \\
RMSE & $3.7122 \%$ & $5.4864 \%$ & $4.8515 \%$ \\
SI & 0.0859 & 0.1196 & 0.1102 \\
CC & 0.991 & 0.9724 & 0.9693 \\
\hline
\end{tabular}
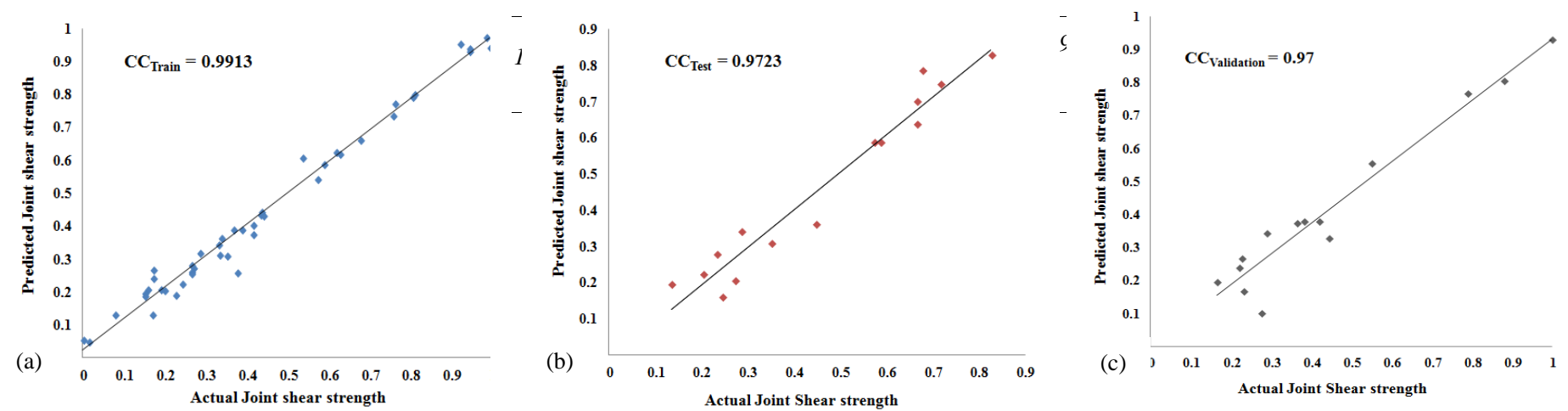

Fig. 3 (a). CC plot for Training data, (b). CC plot for Testing data, (c) CC plot for Validation data and (d) CC plot for predicted and actual values for all data
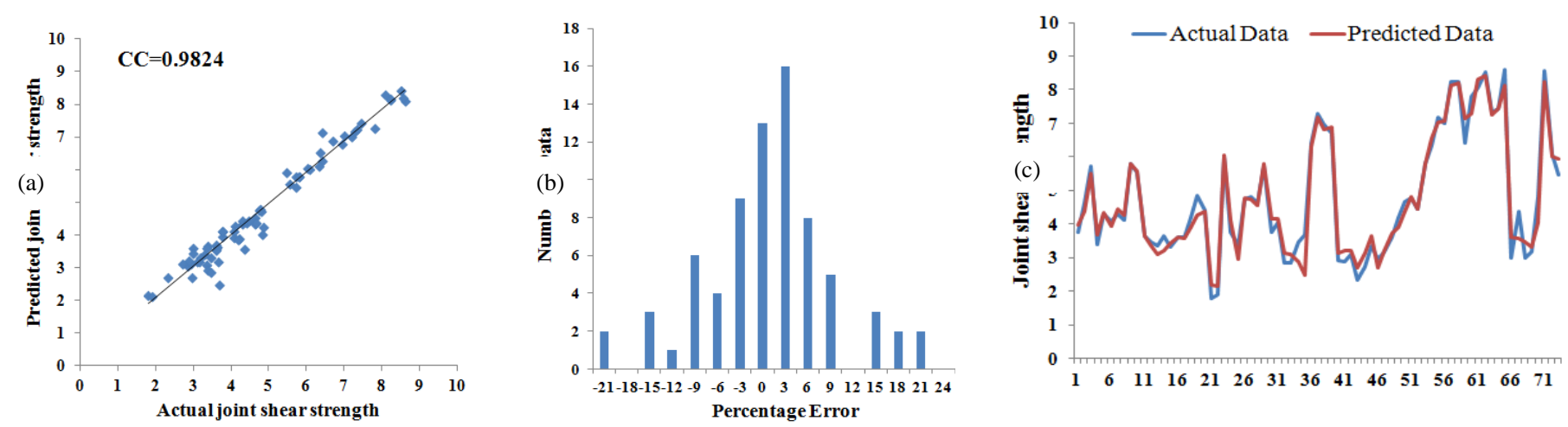

Fig. 4 (a) CC plot for actual values and predicted values of full data set, (b) Error histogram, (c) Graph of predicted v/s accurate shear strength values 
(a)

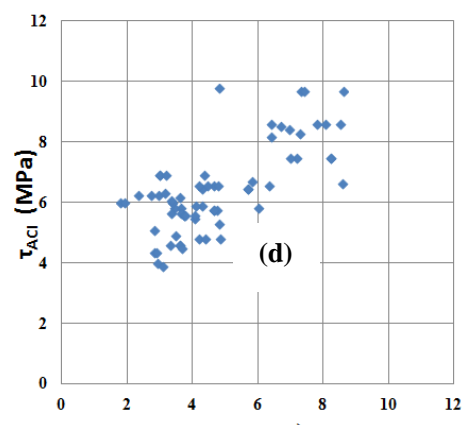

(d) (b)

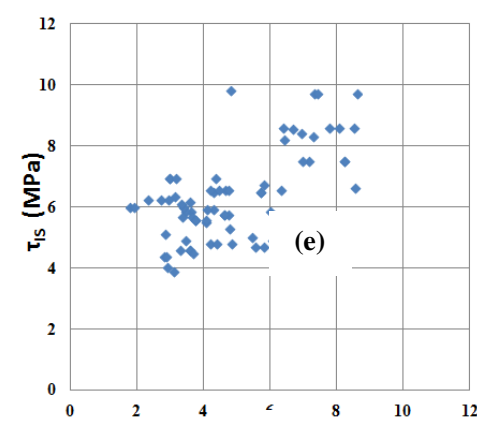

(e)

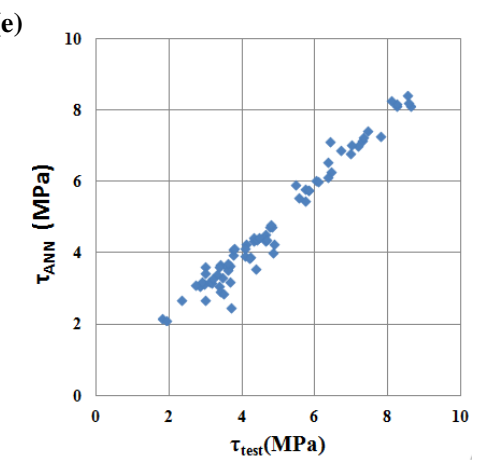

(c)

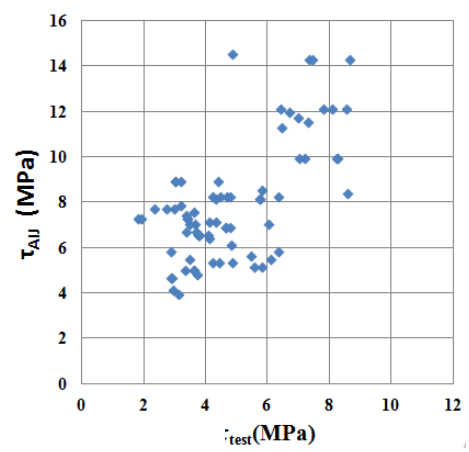

(d)

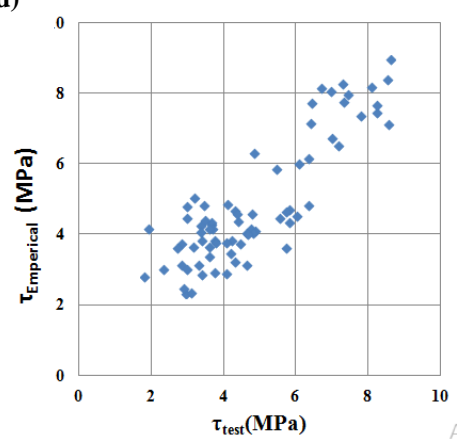

Fig. 5 Plots of the Experimental values from test specimen $\mathrm{v} / \mathrm{s}$ predicted shear strength from different codes and empirical model. [(a)ACI (b)IS (c)AIJ (d)Tung. M (e)ANN]

Average (AVG), Standard deviation (SD) and coefficient of variation (VAR) for Test to predicted data are given Table 3. AVG =1, SD and VAR values nearly equal to zero indicates the accurate prediction. Fig. 5 and Table 3 show that the proposed ANN model shows close agreement with experimental test values compared to other models. The Empirical model also shows better performance compared to results from codes. ACI and IS code predictions are better compared to AIJ predictions.

Table 3. Comparison between The ANN model and other models

\begin{tabular}{llllll}
\hline Model & ACI & IS & AIJ & Tung.M & ANN \\
AVG & 1.4341 & 1.4398 & 1.7792 & 1.039 & 1.0053 \\
SD & 0.4981 & 0.500 & 0.6399 & 0.2565 & 0.089 \\
VAR & 0.2481 & 0.2501 & 0.4096 & 0.0658 & 0.0079 \\
\hline
\end{tabular}


Sustainability, Agri, Food and Environmental Research, (ISSN: 0719-3726), 10(X), 2022: http://dx.doi.org/

\section{CONCLUSION}

1. ANN model is developed to predict the joint shear strength of $B C$ joint subjected to seismic loading. 2. The proposed ANN model shows more stability and accuracy. Hence, the proposed model can be used to predict the joint shear strength of RC exterior beam-column joints subjected to seismic loading.

\section{Acknowledgement}

The authors are thankful to the Director of National Institute of Technology Karnataka, Surathkal and Head of the Department of Civil Engineering for the facilities provided for the investigation.

\section{REFERENCES}

Tung M. Tran, Muhammad N. S. Hadi and Thong M. Pham, "A new empirical model for shear strength of reinforced concrete beam-column connections". ICE Publishing, Magazine of Concrete Research 2014, 66(10), 514-530.

P.G. Asteris, K.G. Kolovos and M.G. Douvika, "Prediction of self compacting concrete strength using artificial neural networks", European Journal of Environmental and Civil Engineering, 2016, Vol. 20, No. S1, s102-s122.

Andres Winston and C. Oreta, "Simulating size effect on shear strength of RC beams without stirrups using neural networks", Engineering Structures 26 (2004) 681-691.

Danial J. Armaghani, Ioanna Z and Panagiotis G, "Soft computing-based techniques for concrete beams shear strength" in ICSI 2019 The 3rd International Conference on Structural Integrity, Procedia Structural Integrity 17 (2019) 924-933.

Mohammed Arafa and Mamoun A. Alqedra ,"Neural Network Models for Predicting Shear Strength of Reinforced Normal and High-strength Concrete Deep Beams", Journal of Applied Sciences · February 2011, DOI: 10.3923/jas.2011.266.274.

J. S. Kuang and H. F. Wong, "Effects of beam bar anchorage on beam-column joint behaviour", Proceedings of the Institution of Civil Engineers Structures \& Buildings 159,April 2006, Issue SB2.

A. G. Tsonos, "Cyclic load behaviour of reinforced concrete beam-column subassemblages of modern structures", WIT Transactions on The Built Environment, Vol 81, 2005 WIT Press, ISSN 1743-3509.

Constantin E. Chalioris, Maria J. Favvata and Chris G. Karayannis, "Reinforced concrete beam-column joints with crossed inclined bars under cyclic deformations", in Wiley InterScience, Earthquake Engng Struct. Dyn. 2008; 37:881-897, 2008, DOI: 10.1002/eqe.793.

Chris G. Karayannis and George M. Sirkelis, "Strengthening and rehabilitation of RC beamcolumn joints using carbon-FRP jacketing and epoxy resin injection" in Wiley 
Sustainability, Agri, Food and Environmental Research, (ISSN: 0719-3726), 10(X), 2022: http://dx.doi.org/

InterScience, Earthquake Eng Struct. Dyn. 2008; 37:769-790, 2008,DOI: 10.1002/eqe.785.

H. F.Wong and J. S.Kuang, "Effects of beam-column depth ratio on joint seismic behaviour", Proceedings of the Institution of Civil Engineers Structures \& Buildings, April 2008, Issue SB2,P:91-101, doi: 10.1680/stbu.2008.161.2.91.

Liu, Cong, "Seismic behaviour of beam-column joint subassemblies reinforced with steel fibres", Master of Engineering thesis at the University of Canterbury, 2006, Christchurch, New Zealand.

Asghar Vatani-Oskouei, "Repairing of seismically damaged RC exterior beam-column connection using CFRP" in Journal of Reinforced Plastics and Composites, 29(21) 3257-3274,2010, DOI: 10.1177/0731684410371407.

Shyh-Jiann Hwang, Hung-Jen Lee, Ti-Fa Liao, Kuo-Chou Wang and Hsin-Hung Tsai, "Role of Hoops on Shear Strength of Reinforced Concrete Beam-Column Joints"in Aci Structural Journal, May 2005, ACI Structural Journal, Title no. 102-S45, V. 102, No. 3.

Costas P. Antonopoulos1 and Thanasis C. Triantafillou, "Experimental Investigation of FRPStrengthened RC Beam-Column Joints" in Journal of Composites for Construction, Vol. 7, No.1, February 1, 2003. ISSN 1090-0268/2003/1-39-49.

D. E. Parker, BEng and P. J. M. Bullman, "Shear strength within reinforced concrete beamcolumn joints" in The Structural Engineer, February 1997 Volume 75/No 418.

Mohammad R Ehsani and Fadel Alameddine, "Design recommendations for type2 High strength reinforced concrete connections" in ACI Structural Journal, 1991, Title No: 88-S30, V.88, No.3.

S. J. Hamil and R.H. Scott, "Connection zone strains in reinforced concrete beam-column connections", University of Durham, UK.

Gerson Moacyr Sisniegas Alva, Ana Lúcia Homce de Cresce El Debs, and Mounir Khalil El Debs, "An experimental study on cyclic behaviour of reinforced concrete connections", in NRC Research Press Website,2007, Can. J. Civ. Eng. 34: 565-575 (2007) doi:10.1139/L06-164.

IS-13920 : 2016 : Ductile design and detailing of reinforced concrete structures subjected to seismic forces-code of practise. ICS 47.020.99;93.140.

ACI-352 : 2002 :"Recommendations for Design of Beam-Column Connections in Monolithic Reinforced Concrete Structures", ACI 352R-02, American Concrete Institute, Farmington Hills, Michigan.

AIJ : 1999 (Architectural Institute of Japan) : Design guideline for earthquake resistance reinforced concrete buildings based on inelastic displacement concept. AIJ, Tokyo, Japan. 
Sustainability, Agri, Food and Environmental Research, (ISSN: 0719-3726), 10(X), 2022 : http://dx.doi.org/

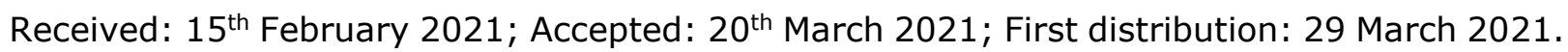

